\title{
Necesidad de un estudio sistemático del fenómeno teatral chaqueño: su importancia e impacto social y cultural para la región
}

Mirna Capetinich

\author{
"La teatralidad o teatralidades son construcciones \\ que funcionan de acuerdo con los códigos culturales \\ del productor y que requieren ser descifradas por el \\ receptor."(Juan Villegas: "De la caducidady \\ renovación de las estrategias para el estudio del teatro", p. 54)
}

No existe hasta la actualidad un estudio sistemático sobre el fenómeno cultural del teatro chaqueño que tienda no sólo a organizar y categorizar sus componentes (grupos de teatro, actores, obras, autores teatrales locales, representaciones, repercusión social), sino también a evaluar desde el presente el proceso histórico en el que se enmarca.

En efecto, en una primera revisión bibliográfica sobre el teatro chaqueño en general, y específicamente de la década del setenta, se pudo detectar que, si bien algunas de las fuentes consultadas ${ }^{1}$ recopilan información sobre las actividades teatrales de la provincia, se traducen en simples crónicas o informes acerca de grupos y experiencias teatrales, pero no persiguen el propósito de categorizar ni de evaluar tales datos desde una perspectiva sistémica e históricocrítica.

No es posible entender y explicar la identidad cultural chaqueña actual si no se rescatan las tradiciones artísticas de la provincia que constituyen factores determinantes en la formación del hombre y la sociedad. El teatro, entendido como "arte de comunicación masiva"2 en tanto genera un diálogo con la sociedad y como uno de los quehaceres culturales que se propone cuestionar, plantear y/o resolver las inquietudes de la condición humana, forma parte de la tradición artística de la provincia del Chaco y toda reconstrucción histórico-crítica sobre él permite arribar a una síntesis y a una perspectiva, con el objeto de contribuir al acervo cultural.

\footnotetext{
1 Como por ejemplo: Revista Todo Teatro en el Chaco, recopilación y sistematización de Mario Guillermo Quinteros, Resistencia, octubre de 1996, pp.27; Publicación 20 Encuentro Provincial de Teatro, Gobiemo de la Provincia del Chaco, Subsecretaría de Cultura, Municipalidad de P. R. Sáenz Peña, A. T. T. A. CH, 1998; Video documental Historia sobre tablas, Resistencia, Chaco, 1994. Asimismo las investigaciones de Guido Miranda, Mariana Giordano, Silvia Rosciani de Leoni citadas en Biliografia aportan solamente referencias históricas y culturales.

2 La concepción de "teatro" como "arte de comunicación masiva" o "vehículo de comunicación" ha sido considerada desde el origen mismo del teatro y manejada a través del tiempo por directores y críticos teatrales diversos. PRIETO STAMBAUGH, Antonio, MUÑOZ GONZÁLEZ, Yolanda: El teatro como vehículo de comunicación, México, Trillas, 1992, pp. 250. Michaud, Guy: "Técnicas del Teatro", traducción de Hilda Torres Varela de L'oeuvre et ses techniques, Paris, Nizet.
} 
Liliana Iriondo, coordinadora de una investigación sobre "La Dramaturgia de las Provincias", -en la que la dramaturgia chaqueña no está contemplada- afirma: "...la realidad teatral de las provincias manifiesta una gran heterogeneidad en la utilización de criterios estéticos, la superposición de diferentes prácticas y la convivencia de variadas textualidades (dramáticas y espectaculares). Si bien Córdoba, Mendoza, Tucumán y Santa Fe expresan una fuerte tradición escénica, en cambio en la región patagónica on el nordeste, para dar dos ejemplos, se está consolidando dicho quehacer." (pp. 51-52).

Es evidente que en su afirmación considera la realidad teatral de la región en la que se ubica el Chaco como una actividad en proceso de consolidación, con respecto a otras provincias del país de "fuerte tradición escénica". He aquí una posible conjetura ante la inexistencia de un estudio sistemático del teatro chaqueño: tal hecho podría deberse a que la provincia no presente una "fuerte tradición escénica".

No obstante, ante dicha apreciación y limitación del corpus de tal investigación, cabe plantearse: ¿desde qué parámetros se puede considerar una "fuerte tradición escénica" en contraposición de un "quehacer teatral en proceso de consolidación"?. ¿El escaso o nulo número de escuelas de Arte Dramático de tales regiones podría ser uno de los factores determinantes de la falta de "fuerte tradición escénica"?. ¿Resulta esta conjetura una limitación para no considerar la tradición teatral de las provincias del nordeste y patagónicas en una investigación teatral sobre las provincias?. ¿O es que tales provincias aún no presentan una identidad teatral?, ¿a qué podría deberse tal carencia?.

A los efectos de contribuir a una reflexión crítica y valorativa sobre la existencia de la identidad teatral chaqueña, se hace necesario, en consecuencia, rescatar la tradición teatral de la provincia del Chaco para descubrir las teatralidades ${ }^{4}$ dominantes a través del tiempo, con el fin de categorizarlas y entender la presente actividad teatral como resultado de dicho proceso.

Ahora bien, cabe preguntarse: ¿cómo iniciar tal estudio sistemático?, ¿desde que perspectiva metodológica podría abordárselo?. La consulta exploratoria de fuentes orales y escritas permitió deducir que la década de 1970 resulta significativa en la tradición teatral chaqueña, pues señala un hito, un antes y un después en la historia teatral, ya que en ella se

\footnotetext{
3 "La Dramaturgia de las Provincias", de Liliana Iriondo en: PELLETIERI, Osvaldo y ROVNER, Eduardo: La Dramaturgia en Iberoamérica: Teoría y Práctica Teatral, Galerna, GETEA/CITI, 1998, pp.. 51-82. E1 resaltado corresponde a la autora del presente trabajo.

4 Se toma el concepto de "teatralidades" de Juan VILLEGAS: “(...) Las teatralidades se entienden como una serie de imágenes visuales, imágenes que son portadoras de mensajes y constructoras o integrantes de un imaginario social. Este imaginario social incluye tanto un modo de percibir visualmente el mundo como modos de conducta gestual y espectacular. La teatralidad o las teatralidades son construcciones que funcionan de acuerdo con los códigos culturales del productor y que requieren ser descifradas por el receptor. Es una construcción cultural de sectores sociales que codifican su modo de percepción del mundo y su modo de autorrepresentarse en el escenario social." VILLEGAS, Juan (University of California), "De la caducidad y renovación de las estrategias para el estudio del teatro", p.54, en Osvaldo Pellettieri, editor, El teatro y su crítica, Buenos Aires, Galerna, Facultad de Filosofia y Letras (U.B.A), 1998, pp. 296.
} 
logra institucionalizar la actividad teatral, se toma conciencia de la profesionalización del actor chaqueño y comienza a quedar atrás la época del teatro "vocacional"s.

La década del setenta, caracterizada, por una parte y a nivel mundial, por una "explosión cultural"; por otra parte y desde el punto de vista político, signada por la preeminencia de los regimenes totalitarios latinoamericanos ${ }^{7}$ tendentes a censurar las libertades de expresión y pensamiento, resulta propicia justamente para el desarrollo de la actividad teatral. El teatro se convierte en un medio para canalizar inquietudes, intereses, ideologías opuestas al poder oficial, cumple una función eminentemente social y, por lo general, política. El teatro chaqueño de tal década no escapa a dicha explosión cultural, cobra trascendencia en la sociedad, a través de la labor pedagógica de Carlos Schwaderer y Gladis Gómez, de la actividad teatral desarrollada en centros culturales importantes de Resistencia, como el Fogón de los Arrieros ${ }^{9}$, la Peña Nativa Martín Fierro ${ }^{10}$, de instituciones, como el Departamento de

\footnotetext{
5 El teatro "vocacional" o "informal" se refiere a la actividad teatral intuitiva, por placer y firme vocación, sin conocimiento cabal y aplicación de la técnica teatral, que comenzaron los pioneros del teatro chaqueño. Al respecto merece citarse el pensamiento del ingeniero Emilio Stern, quien dirigió la Academia de Arte Escénico de Resistencia hacia 1941, transformada luego en Teatro de Arte de Resistencia. En la revista "Boreal", abril 1947, Stern manifiesta: "...el Teatro de Arte de Resistencia no pretende ser un teatro experimental. No tiene sentido ensayar nuevos métodos de exposición o estrenar teatro de vanguardia en un ambiente carente de experiencia teatral, falto de actores formados, escaso de recursos económicos para la instalación de los medios técnicos modernos y no teniendo directores avezados en el dificil arte de la puesta en escena. Lo que se busca es hacer buen teatro, teatro honesto y noble, dignamente presentado y estudiado hasta el fondo en todos sus detalles de interpretación, para ser educador verdadero del pueblo", p.26, cit. por Guido MIRANDA en: Fulgor del Desierto Verde (1925-1947), Resistencia, Ed. Región, 1985. Asimismo es pertinente considerar otro testimonio oral de Hilda Torres Varela, actual directora del Fogón de los Arrieros, centro cultural de trascendencia provincial, nacional e internacional desde su creación, en el que durante 19441977 se destacó una incesante labor del "teatro leído", luego "Teatro del Fogón": "Al principio, todos los martes, Aldo (Boglietti) hacia hablar a alguien del pueblo sobre algún tema de interés, y eso fue dando alguna continuidad, pero él nunca pensó que eso era actividad cultural, ni que estaba haciendo cultura. (...) Y lo mismo cuando se hacía teatro leido desde el '49 en el Fogón. Era todo informal.". Entrevista a Hilda Torres Varela, Resistencia, 22 de abril de 1997, referida por Mariana GIORDANO en su libro Los Murales Chaqueños. Del Fogón de los Arrieros a la Plaza 25 de Mayo, Cuadernos de Geohistoria Regional N ${ }^{\circ} 34$, IIGHI, Conicet, Resistencia, Chaco, 1998.

"Es sabido el desarrollo de la cultura que se dio en el mundo, desde las ideologías y las artes, a partir del "paradigma" Estados Unidos, potencia mundial a nivel político, económico, cultural, en tal etapa histórica. "Cuando hablamos de la década del setenta, no podemos dejar de remitirnos a la explosión cultural producida en el mundo en ese momento. Algunos pensadores consideran que más que una "explosión"se debe entender que en esta época se consolidó EE. UU. No sólo como potencia mundial en el campo político y económico, sino también como eje cultural del mundo. Fue la época de cambios en la sociedad estadounidense; aparecieron los "hippies", los Beatles en la música, en pintura el Pop Art, la Colourfield Painting, el Minimal Art. Es la llamada "New Wave", el "idealismo" de la era Kennedy, la época en que el mundo tenía sus ojos puestos en EE.UU, y en todo lo que éste mostraba y "vendia"." De: Mariana GIORDANO en: "La Politica Oficial de la Cultura en el Chaco en el periodo 1967-1983", en: XIV Encuentro de Geohistoria Regional. Resistencia, IIGHI, 1994, p. 154.

${ }^{7}$ Cfr. p. 554 de Stephen Jay Gould: "El Mundo en 1970. Un lobo en la puerta. El medio ambiente se convierte en protagonista", en: El Gran Libro del Siglo. Título original Our Times. Traducción y documentación para la edición española de Teresa Florit Selma. Arte Gráfico Editorial Argentino, Barcelona, pp. 508-575.

${ }^{8}$ Esta pareja actoral, y matrimonial en aquella época, habia estudiado Formación y Dirección Actoral en la Escuela de Ariel Bufano (Buenos Aires) y, a partir de su capacitación profesional, promueve en la región la conciencia de la "profesionalización del actor".

${ }^{9}$ La labor del Teatro del Fogón trascendió no sólo en la provincia sino también a nivel nacional, como "uno de los más destacados teatros independientes del interior del pais". "Los primeros cincuenta años del teatro en Resistencia", de Maria Silvia Leoni de Rosciani, en: Suplemento Galería de El Diario, Resistencia, 9/IV/2000.
} 
Extensión Universitaria y Ampliación de Estudios de la Universidad Nacional del Nordeste y el

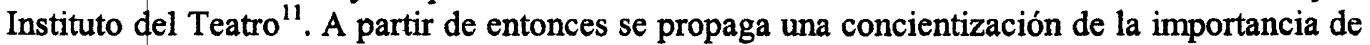
la concepción del teatro como medio de vida, como profesión y no como vocación simplemente, tal como se lo concebía en décadas anteriores.

En razón de lo expuesto, se considera una alternativa válida, iniciar una línea de investigación teatral tomando como punto de partida la década del setenta, señada por una importante actividad cultural teatral, considerando sus antecedentes desde 1967 y sus proyecciones hasta 1983 . Con el objeto de constatar tales datos, conviene referir sintéticamente antecedentes relevantes del fenómeno teatral chaqueño de tal década.

En principio, desde 1969, año en que la provincia del Chaco, representada por el grupo de teatro de la Universidad Nacional del Nordeste -"centro de las actividades intelectuales y artísticas" de la provincia en el período $1956-1967^{12}-$ logra a nivel nacional el máximo galardón "Premio Elefante de Oro", en el "Festival Nacional de Espectáculos para Niños" "13, llevado a cabo en la ciudad de Necochea, comienza a vivirse lo que se conoce como "época gloriosa"del Teatro Universitario".

Cabe considerarse además que durante el período 1967-1983, desde la Dirección de Cultura $^{15}$-luego Subsecretaría y más adelante Ministerio- se promueve una incesante actividad

${ }^{10}$ Al respecto de la actividad de la Peña Martín Fierro durante 1976, Alba Dellamea de Prieto sefiala: "En este año se intensificará una actividad ya abordada en otras oportunidades como el teatro, que tuvo en El Tablado y Poen Alarcón un eximio representante. Se iniciará el ciclo de la Peña Teatral (...) a cargo de intérpretes de dilatada actuación escénica, como Edna M. Obal, Carlos Shwaderer y Gladis Gómez", en: Obra y Proyección de la Peña Nativa Martín Fierro, Resistencia, 1990

11 Acerca de estas instituciones se especifica más adelante. (Véanse párrafos sucesivos).

12 Se han considerado las periodizaciones que desde una perspectiva institucional propone la Licenciada María Silvia LEONI de ROSCIANI en su artículo "El campo cultural chaqueño. Un análisis institucional", en: XV Encuentro Regional de Geohistoria Regional, Gobernador Virasoro, Corrientes,1995, pp. 193-202.

13 Se logra tal premio con la obra Puff, el fantasmita, de la autora brasileña María Clara MACHADO, y la dirección teatral de José Luis Andreoni, quien había llegado desde Buenos Aires a fines de 1968. El Teatro Universitario (T. U. N. N. E. ) recibe entonces esta nómina de premios: Mejor Espectáculo Teatral, Primer Premio Revelación del Festival (otorgado a la joven Gladis Gomez, quien años más tarde, ya graduada en Buenos Aires, promoverá una importante labor en el teatro chaqueño) y Mención Especial del Consejo Nacional de Educación por el contenido didáctico de la obra.

14 Tal "época" se caracteriza porque, según Maria D. Cristófani, actual Subsecretaria de Cultura del Gobierno de la Provincia del Chaco, ex - integrante del elenco del Teatro Universitario del Nordeste: " Fue la época de auge y plenitud del Teatro Universitario, la época "gloriosa", ya que contábamos con profesionales de destacada trayectoria a nivel nacional e internacional, una infraestructura edilicia envidiable y recursos técnicos muy importantes. Nosotros mismos, actores y técnicos, habiamos construido el telón verde del escenario del Aula Magna. Teniamos un vestuario a la altura del de los grandes teatros de Buenos Aires, como el Teatro Colón. Habia una cantidad de spots, utilería, etc., todo delicadamente categorizado, ordenado y mantenido. Hasta el '73 en que asume el gobierno peronista, fue una "época gloriosa", irrepetible en la historia del Teatro Universitario". Entrevista a María D. Cristófani, Resistencia, 30 de marzo de 2000. El actual Director del Teatro Universitario, ex - integrante del elenco del Teatro Universitario de tal década, recuerda: "Fue la "época de oro" del T. U. N. N. E. Nos habia apoyado el Fondo Nacional de las Artes con máquinas de coser, amplia gama de spots, pelucas de alta calidad, entre otras cosas. Fue la "época gloriosa", única e incomparable, nunca más vuelta a vivir". Entrevista a Coco Barreda, Resistencia, 31 de marzo de 2000.

${ }^{15}$ A cargo de la Sra. Lilia Yolanda Pereno de Elizondo, junto a su colaborador Ercilio Castillo, durante los primeros catorce años; y posteriormente, a cargo de José del Carmen Nieto. Al respecto de la labor de la Sra. de Elizondo, en el discurso en homenaje a su memoria del Doctor Adolfo A. Petraglia publicado en NORTE (6/IX/81), se señala: "En 
cultural en organismos oficiales y privados, a la cual la actividad teatral no es ajena, ya que adquiere un destacado lugar en la capital y en el interior de la provincia. Se trata de un período en el que se toma conciencia de la profesionalización del actor, en principio, a través de talleres y cursos de perfeccionamiento dictados en la Universidad por destacados directores de teatro provenientes de Buenos Aires y de Córdoba ${ }^{16}$, junto con distinguidos profesionales del medio ${ }^{17}$; y más tarde, desde 1976, a raiz de cursos de perfeccionamiento de dos actores y directores chaqueños graduados en Buenos Aires, como Carlos Schwaderer y Gladis Gómez, quienes en 1978 crean en Resistencia el Instituto del Teatro. Su labor, principalmente de los cursos de perfeccionamiento y talleres, es altamente valiosa pues forman a una serie de actores -algunos de los cuales luego trascienden a nivel nacional e internacional ${ }^{18}$-que paulatinamente van generando diversos grupos de teatro independiente ${ }^{19}$, sobre todo a partir de 1983, cuando el advenimiento de la democracia, instaura mayor libertad de acción, la cual origina una consecuente y significativa multiplicación de grupos de teatro.

Una posible vía de abordaje metodológico para efectuar una investigación teatral chaqueña, podría ser la perspectiva hermenéutico-fenomenológica ${ }^{20}$. Esto es, una metodología consistente en realizar, en principio, una percepción fenomenológica o lectura totalizadora $e$ intuitiva del fenómeno teatral chaqueño del período señalado; en segundo lugar, un análisis formal del corpus teatral, lo que implica un estudio semántico y de relacionamiento simbólico

1967 por una inteligente y acertadisima resolución gubernamental se la designa al frente del organismo Provincial de Cultura (...) Desde ese momento y por primera vez en la historia cultural del Chaco tuvimos un funcionario compenetrado profunda e intimamente de las necesidades que hacen a la elevación espiritual de una comunidad tan polifacética como la nuestra. (...), la señora Yolanda fue cubriendo en unos casos y estimulando en otros las necesidades y apetencias estéticas de cuanto ser humano en el Chaco demostrara poseerlas. Afloraron así valores desconocidos, latentes y en gestación que a poco de exteriorizarse fueron dando un realce al Chaco cultural (...)", op. cit. Guido MIRANDA, pp. 16-17. Acerca de la labor de Nieto, Mariana GIORDANO refiere en su artículo "La Politica Oficial de Cultura en el Chaco en el Período 1967-1983", publicado en XIV Encuentro de Geohistoria Regional, Resistencia, Chaco, 1994, IIGHI, p.164: “(...)La politica implementada por Nieto tendió a consolidar la labor de asistencia artística y asistencia técnica consolidada en los años anteriores, incrementar el apoyo al interior, realizar programas de difusión cultural (industrias culturales) y proteger el patrimonio cultural chaqueño. (...). El contacto con el interior se incrementó, pero a la vez pasó a ser permanente, no sólo por las Comisiones de Cultura (...), sino principalmente por la labor de promotores culturales,...".

${ }^{16}$ Directores provenientes de Buenos Aires fueron: Roberto Conte, José Luis Andreoni, Julián Romeo, Bernardo Roitman, y de Córdoba: Héctor Veronese.

${ }^{17}$ Como por ejemplo: Betty Honorat de Esquivel, Maria Luisa Acuña, María Josefa P. W. de Tamburini, M. de Cedrán, Eduardo Bértola, Saulo Benavente, Patricia Stokoe, José Ramírez, Amanda C. de Hotes, Omar Lagomarsino, Oscar Castro, Ana Maria Kedinger de Risotti, quienes tenían a su cargo materias como Expresión Corporal, Esgrima y Rítmica; Cultura Grecolatina; Historia del Teatro; Filosofia del Arte; Música; Escenografia; Técnicas de la Danza Clásica; Yoga; Iluminación; Canto Coral; Educación Vocal. Entrevista a Gladis Gómez, Resistencia, 29 de marzo de 2000.

${ }^{18}$ Ejemplos de estos casos lo constituyen: José Fuentes, quien actualmente está dedicado a la televisión en Buenos Aires; Pepe Jiménez, dedicado a la dirección y actuación, también en Buenos Aires; y Cacho Sixto, quien hoy reside en París y tiene a su cargo una Escuela de Arte. Entrevista a Gladis Gómez, Resistencia, 29 de marzo de 2000.

${ }_{19}$ Tal es el caso de Hugo Blotta, Carlos Canto, Emilce Isnardo, entre otros.

${ }^{20}$ Se toma como modelo de propuesta metodológica para el abordaje de la obra literaria la referida por Graciela Maturo en Introducción a una hermenéutica del texto. Buenos Aires, Tekné, 1995. Asimismo se consideran como referencia teórico-metodológica válida los aportes de Osvaldo PELLETIERI, quien esboza un "modelo de periodización para el teatro argentino" en: Teatro y Teatristas, Ensayo sobre teatro argentino e iberoamericano. Buenos Aires, Galerna, Facultad de Filosofia y Letras (UBA), 1992, pp. 69-82. 
de la producción teatral y los contextos de producción y de recepción; y por último, una exégesis hermenéutica o nueva lectura integradora, cuyo objetivo sea desentrañar las teatralidades dominantes y sus significaciones en el contexto social y cultural chaqueño y argentino.

Resumiendo, una reconstrucción histórico-crítica sobre la actividad teatral del Chaco de la década del '70, considerando sus antecedentes y proyecciones, contribuirá a aportar una posible solución al problema de la inexistencia de un estudio sistemático del fenómeno teatral chaqueño y a fortalecer el acervo cultural de tal provincia. Permitirá a las nuevas generaciones teatrales comprender la actual realidad teatral chaqueña, reconociendo desde el presente las bases o raíces de la tradición. Brindará además un catálogo de la dramaturgia local, que podrá ser objeto de consulta, análisis y crítica, tanto en ámbitos universitarios, en instituciones relacionadas con actividades teatrales, como en ámbitos de Educación General Básica y de Polimodal.

En concreto, existe el legítimo derecho de una cultura de sobrevivir reinterpretándose a sí misma. Se propone pues, desde este espacio, promover una línea de investigación teatral chaqueña con el objeto de rescatar, a través de una sistematización y consecuente evaluación, una tradición artística provincial significativa en la formación del hombre y la sociedad, lo cual ayudará a dilucidar la identidad cultural de la provincia. El hecho de contribuir a fortalecer desde la misma región una crítica constructiva tendente a mejorar, ampliar, crear, incentivar la propia dramaturgia y espectacularidad teatral de la provincia, justifica - sin duda alguna- el impacto social y cultural para la propia región. 


\section{BIBLIOGRAFIA CONSULTADA:}

Sobre teoría literaria y teatral:

GONZÁLEZ DE DÍAZ ARAUJO, Graciela, MARTÍ, Sonia y otros: Teatro, adolescencia y escuela, Fundamentos y práctica docente. Buenos Aires, Aique, $1^{\mathrm{a}}$ ed. , 1198, pp. 174.

IRIONDO, Liliana: "La Dramaturgia de las Provincias", en: PELLETIERI, Osvaldo y ROVNER, Eduardo, editores: La Dramaturgia en Iberoamérica: Teoría y Práctica Teatral. Buenos Aires, Galerna, GETEA / CITI, 1998, pp.51-82.

LYOTARD, Jean F. : La Fenomenología. Buenos Aires, Ed. Universitaria, 1960, pp. 61.

MATURO, Graciela: Introducción a una Hermenéutica del Texto. Buenos Aires, Ed. Tekné, $2^{\text {a }}$. Ed. , 1995, pp. 110.

MICHAUD, Guy: L'oeuvre et ses techniques. Paris, Nizet, Traducción de Hilda Torres Varela, pp. 3-23.

PAVIS, Patrice: Diccionario del teatro. Barcelona, Piadós, $1^{\text {a }}$ ed. , 1998, pp. 512.

PELLETIERI, Osvaldo (Editor): Teatro y Teatristas, Ensayo sobre teatro argentino $e$ iberoamericano. Buenos Aires, Galerna, Facultad de Filosofia y Letras (UBA), 1992, pp. 6982.

PRIETO STAMBAUGH, Antonio, MUÑOZ GONZÁLEZ, Yolanda: El teatro como vehiculo de comunicación. México, Trillas, 1992, pp. 250.

ÜBERSFELD, Anne: Semiótica Teatral. Madrid, Ed. Cátedra,1989, pp. 211.

VILLEGAS, Juan: "De la caducidad y renovación de las estrategias para el estudio del teatro", en: PELLETIERI, Osvaldo, editor: El Teatro y su critica. Buenos Aires, Galerna, Facultad de Filosofia y Letras (UBA), 1998, pp. 47-56. 
Sobre contexto histórico mundial:

GOULD, Stephen: "El Mundo en 1970. Un lobo en la puerta. El medio ambiente se convierte en protagonista", en: El Gran Libro del Siglo. Título original: Our Times. Traducción y documentación para la edición española de Teresa Florit Selma. Arte Gráfico Editorial Argentino, Barcelona, pp. 508-575.

Sobre contexto histórico y cultural chaqueño:

ALTAMIRANO, Marcos y otros: Historia del Chaco. Resistencia, Dione, 1987, pp. 310-328.

DELlaMEA de PRIETO: Obra y proyección de la Peña Nativa Martín Fierro. Resistencia, $1990,25-35$

GARCÍA PULIDO, José y otros: El Chaco Actual. Resistencia, Colmegna, 1978, 121-127.

GIORDANO, Mariana: Los Murales Chaqueños. Del Fogón de los Arrieros a la Plaza 25 de Mayo. Resistencia, Cuadernos de Geohistoria Regional N³4, IIGHI, Conicet,1998, pp.7-12.

: "La Politica Oficial de Cultura en el Chaco en el Periodo 1967-1983", en: XIV Encuentro de Geohistoria Regional. Resistencia, IIGHI,1994, pp. 153-164.

: "El Ambiente Cultural Chaqueño en la primera mitad del Siglo XX", en: XIV Encuentro de Geohistoria Regional. Resistencia, IIGHI, 1996, pp. 184-200.

LEONI de ROSCIANI, María Silvia: "El Campo Cultural Chaqueño. Un Análisis Institucional", en: XV Encuentro de Geohistoria Regional. Corrientes, 1995, pp. 193-205.

MAEDER, Ernesto: Historia del Chaco.Buenos Aires, Plus Ultra, 1996, (18), pp.271-295.

MIRANDA, Guido: Fulgor del Desierto Verde (1925-1947). Resistencia, Región, 1985, pp. 931. 
TORRES VARELA, Hilda: "Un Fogón para la nostalgia", en: SECRETARÍA DE CULTURA DE LA NACIÓN, Juan de Dios Mena. Buenos Aires, 1986, pp. 11-15.

\section{Fuentes orales consultadas:}

Entrevista a Coco Barreda (actual Director del Teatro Universitario de la U.N.N.E), Resistencia, Chaco, 31 de marzo de 2000.

Entrevista a Hugo Blotta (actual Presidente de la Asociación de Técnicos Teatrales y Actores del Chaco), Resistencia, Chaco, 28 de marzo de 2000.

Entrevista a Maria D. Cristófani (actual Subsecretaria de Cultura de la Provincia del Chaco, ex - integrante del Teatro Universitario de la U. N. N. E.), Resistencia, Chaco, 30 de marzo de 2000.

Entrevista a Gladis Gómez (actriz y directora teatral chaqueña), Resistencia, Chaco, 29 de marzo de 2000.

Fuentes audiovisuales ( vídeo documental):

Historia sobre tablas, Resistencia, Chaco, 1994. 